\title{
BRCA1 methylation in newborns: genetic disposition, maternal transfer, environmental influence, or by chance only?
}

Per Eystein Lønning ${ }^{1,2^{*}}$ and Stian Knappskog ${ }^{1,2}$ (1)

\begin{abstract}
In this letter, we respond to and discuss the recent publication by Al-Moghrabi et al.: Methylation of BRCA1 and MGMT genes in white blood cells are transmitted from mothers to daughters. We discuss their findings with emphasis on two other recently published papers and argue that their data allows no conclusion regarding the transmission of BRCA1 methylation from parent to child.
\end{abstract}

Keywords: BRCA1, Hypermethylation, Constitutive methylation, Ovarian cancer, Breast cancer, White blood cells

The recent publication by Al-Moghrabi et al. [1] reporting BRCA1 methylation in a significant number of newborn girls reveals interesting data. Many of their findings are consistent with recent data reported by our group [2].

Analyzing 295 newborns, Al-Moghrabi and colleagues found WBC BRCA1 promoter methylation in 9.9\%. Similarly, among $n=611$ newborns, we found BRCA1 methylation in $7.0 \%$. Among healthy controls aged $15-$ 50 years, they found BRCA1 methylation among 25 out of 268 women (9.3\%), somewhat contrasting our finding of methylation among 153 out of 3602 (4.2\%) of adult healthy women, with a slight reduction during aging. This contrast may have methodological explanations. Considering the methods applied in the two studies, they differ somewhat in respect to which CpGs that were included in the different assays. While the same primers are used in Al-Moghrabi and colleagues' MSP-assay, our qPCR assay includes a probe covering three additional CpGs. Although qPCR is typically more sensitive than MSP, it may be that the higher number of CpGs covered results in a more stringent threshold for positive reactions. This is depicted in Fig. 1. Notably, the two studies were also conducted in different parts of the world, and

\footnotetext{
* Correspondence: per.lonning@helse-bergen.no

${ }^{1}$ Department of Clinical Science, University of Bergen, Bergen, Norway 2Department of Clinical Oncology, Haukeland University Hospital, Bergen, Norway
}

(c) The Author(s). 2018 Open Access This article is distributed under the terms of the Creative Commons Attribution 4.0 International License (http://creativecommons.org/licenses/by/4.0/), which permits unrestricted use, distribution, and reproduction in any medium, provided you give appropriate credit to the original author(s) and the source, provide a link to the Creative Commons license, and indicate if changes were made. The Creative Commons Public Domain Dedication waiver (http://creativecommons.org/publicdomain/zero/1.0/) applies to the data made available in this article, unless otherwise stated. influence, including diet [3] as well as ethic differences. Thus, there are examples of biologically functional SNPs, like the MDM2 SNP285G/C variant, affecting cancer risk [4], that is limited to certain ethnic groups [5].

Notably, analyzing samples by pyrosequencing, we found BRCA1 methylation to be mosaic, in most cases affecting less than $10 \%$ of the BRCA1 alleles. However, comparing methylation frequency among newborns to adults (control population of $n=3602$ with the addition of a separate group of 292 young females reported in our study), the difference in methylation frequency between newborns and adults was highly significant (Fisher's exact test; $p=0.0021$ ). While we had no access to repeated sampling over time in individuals, this finding is consistent with constitutional methylation but with a slight loss during lifetime. Thus, constitutional methylation patterns are known to change with age [6-8].

What are the potential implications of these findings? While several small studies have indicated normal tissue BRCA1 methylation to be associated with an elevated risk of breast cancer in general $[9,10]$ and early breast cancer [11], a final conclusion warrants evaluation in larger cohorts. As for ovarian cancer, analyzing two independent cohorts of 934 ovarian cancer patients versus 1698 controls and 607 patients versus 1984 controls [2], we found WBC BRCA1 methylation to be associated 


\section{GGTTAGAGGGTAGGTATTTTATGGTAAATTTAGGTAGAATTTTTTTTTTTTYGTTTTTTTTTTTTTAY GTTATTYGGGGGTAGATTGGGTGGTTAATTTAGAGTTTYGAGAGAYGTTTGGTTTTTTTTGTTTTTTT TATTTTTTGATTGTATTTTGATTYYGTATTTGAGAGGTTGTTGTTTAGYGGTAGTTTTTTGGTTTTY GTGGTAAYGGAAAAGYGYGGGATTATAGATAAATTAAAATTGYGATTGYGYGGYGTGAGTTYGTTGA \\ GATTTTTTGGAYGGGGGATAGGTTGTGGGGTTTTTTAGATAATTGGGTTTTTGYGTTTAGGAGGTTTT}

Fig. 1 Region of the BRCA1 promoter (bisulfite converted) covered by the MSP assay performed by Al-Moghrabi et al. [1] and the qPCR assay performed by Lønning et al. [2]. CpG dinucleotides (potential methylation sites) are highlighted in yellow and " $Y$ " indicates that the C in CpG could be either $\mathrm{C}$ or $\mathrm{T}$ after bisulfite conversion. Primers used in both assays are highlighted by gray background. The additional probe used by Lønning et al. is highlighted by green background and red font

with an OR of 2.91 (95\% CI 1.85-4.56) and 2.22 (95\% CI 1.40-3.52), respectively, for high-grade serous ovarian cancer. In contrast, no elevated risk for either low-grade serous ovarian cancer or ovarian cancers harboring other histologic types was detected. These findings further emphasize the potential biological and clinical implications of the results from Al-Moghrabi and colleagues.

The findings, however, raise a number of questions remaining to be addressed. While in our study, BRCA1 methylation revealed a trend to become less frequent with age across all age groups; the major difference between newborns and adults seemed to occur during the first two decades of life. Thus, while BRCA1 methylation has been found associated with cancer risk, notably, the ORs have been calculated based on age-matched controls; thus, methylation at birth may not automatically be inferred as a risk factor. We lack definite evidence confirming that individuals carrying BRCA1 methylation at age 60 carried the same methylation status at birth, although it may be reasonable to assume so. Most cancers likely develop for years before becoming clinically detectable; thus, the finding of an elevated OR for cancer associated with BRCA1 methylation suggests this methylation has been present for a substantial time period.

The final question relates to the potential cause of constitutional BRCA1 methylation. In a recent paper, Evans et al. [12] reported a 5'UTR variant in the BRCA1 promoter to be associated with methylation. Analyzing 49 families with a high incidence of breast and/or ovarian cancer, WBC promoter methylation was detected in two index patients. In these two families, constitutive BRCA1 methylation was associated with the $5^{\prime} \mathrm{UTR}$ variant. The BRCA1 methylation was detected in tissue across all three germ layers. Importantly, in these individuals, methylation was detected in $100 \%$ of the $5^{\prime}$ UTR-variant-containing $B R C A 1$ alleles. While our finding of BRCA1 methylation among healthy carriers [2] also could be associated with genetic variants, several lines of indications argue against such an explanation. Firstly, we found a low incidence of methylated alleles $(<10 \%)$, indicating mosaicism. Secondly, the incidence of affected individuals in the population was much higher (4\%). Third, the OR for high-grade serous ovarian cancer of 2-3, contrasting the high-risk families reported by Evans et al. Finally and importantly, we found $B R C A 1$ methylation in both ancient BRCA1 haplotypes. While these findings argue against influence from a single cis-acting factor, it does not exclude the possibility that certain SNP variants may be associated with an elevated risk of $B R C A 1$ promoter methylation. Further studies are warranted to clarify this issue.

In the title of their manuscript, Al-Moghrabi et al. advocate a mother to daughter transmission of $B R C A 1$ methylation. Among 20 BRCA1 methylated mothers, in 290 mother-daughter pairs, they found WBC methylation in 4 of their daughters (20\%). From the figures presented in their Table 1, it is not possible to extract how many of the daughters in the 290 mother-daughter pairs that harbored methylation, but 30 out of a total of 302 newborns were found methylated. Assuming these 30 to be among the 290 daughters in mother-daughter pairs, the number of methylated daughters without methylated mother will be 26 out of 270 (9.6\%). Testing the hypothesis that BRCA1 methylation is transmissible from mother to daughter, based on these data, yields a $p$ value $>0.10$ (Fisher's exact test). In the extreme and unlikely case that a maximum number of methylated newborns $(n=12)$ are not among the 290 mother-daughter pairs, one would still only reach a $p$ value of 0.03 . While their hypothesis suggesting an association between $B R C A 1$ methylation status in mothers and daughters is interesting, we are concerned that the number of observations reported does not allow any statement in this respect for the moment. But we encourage Al-Moghrabi and co-workers to release all details of their observations so that formal statistical assessment can be made. Further, it is important to note that we currently lack data from males (newborns as well as fathers), which may also be needed to address the topic of methylation transmission.

Summarizing the evidence, while germline mutations, as reported by Evans and colleagues, may be associated with $B R C A 1$ constitutive methylation, most likely, this accounts for a small fraction of affected individuals only. 
As for the rest, we lack conclusive information regarding the cause as well as the risk of potential transmission between parents and children. In this respect, apart from a higher incidence of constitutive methylation in the general population, current findings for BRCA1 methylation resemble previous findings for $M L H 1$ methylation and the risk of colorectal cancer $[13,14]$.

\section{Authors' contributions}

PEL performed statistical assessments and wrote the manuscript. SK performed statistical assessments and wrote the manuscript. Both authors read and approved the final manuscript.

\section{Competing interests}

The authors declare that they have no competing interests.

\section{Publisher's Note}

Springer Nature remains neutral with regard to jurisdictional claims in published maps and institutional affiliations.

Received: 21 August 2018 Accepted: 10 October 2018

Published online: 22 October 2018

References

1. Al-Moghrabi N, Al-Showimi M, Al-Yousef N, Al-Shahrani B, Karakas B, Alghofaili $L$, et al. Methylation of BRCA1 and MGMT genes in white blood cells are transmitted from mothers to daughters. Clin Epigenetics. 2018;10:99.

2. Lønning PE, Berge EO, Bjornslett M, Minsaas L, Chrisanthar R, Hoberg-Vetti $\mathrm{H}$, et al. White blood cell BRCA1 promoter methylation status and ovarian cancer risk. Ann Intern Med. 2018;168(5):326-34.

3. Supic G, Jagodic M, Magic Z. Epigenetics: a new link between nutrition and cancer. Nutr Cancer Int J. 2013;65(6):781-92

4. Knappskog S, Bjornslett M, Myklebust LM, Huijts PE, Vreeswijk MP, Edvardsen $\mathrm{H}$, et al. The MDM2 promoter SNP285C/309G haplotype diminishes Sp1 transcription factor binding and reduces risk for breast and ovarian cancer in Caucasians. Cancer Cell. 2011;19(2):273-82.

5. Knappskog S, Gansmo LB, Dibirova K, Metspalu A, Cybulski C, Peterlongo P, et al. Population distribution and ancestry of the cancer protective MDM2 SNP285 (rs117039649). Oncotarget. 2014;5(18):8223-34

6. Jones MJ, Goodman SJ, Kobor MS. DNA methylation and healthy human aging. Aging Cell. 2015;14(6):924-32.

7. Pal S, Tyler JK. Epigenetics and aging. Sci Adv. 2016;2(7):e1600584 1-19.

8. Fraga MF, Ballestar E, Paz MF, Ropero S, Setien F, Ballestart ML, et al. Epigenetic differences arise during the lifetime of monozygotic twins. Proc Natl Acad Sci U S A. 2005:102(30):10604-9.

9. Iwamoto T, Yamamoto N, Taguchi T, Tamaki Y, Noguchi S. BRCA1 promoter methylation in peripheral blood cells is associated with increased risk of breast cancer with BRCA1 promoter methylation. Breast Cancer Res Treat. 2011;129:69-77.

10. Al-Moghrabi N, Nofel A, Al-Yousef N, Madkhali S, Bin Amer SM, Alaiya A, et al. The molecular significance of methylated BRCA1 promoter in white blood cells of cancer-free females. BMC Cancer. 2014:14:830.

11. Wong EM, Southey MC, Fox SB, Brown MA, Dowty JG, Jenkins MA, et al. Constitutional methylation of the BRCA1 promoter is specifically associated with BRCA1 mutation-associated pathology in early-onset breast cancer. Cancer Prev Res. 2011:4(1):23-33.

12. Evans DGR, van Veen EM, Byers HJ, Wallace AJ, Ellingford JM, Beaman G, et al. A dominantly inherited 5' UTR variant causing methylation-associated silencing of BRCA1 as a cause of breast and ovarian cancer. Am J Hum Genet. 2018;103(2):213-20.

13. Hitchins MP, Rapkins RW, Kwok CT, Srivastava S, Wong JJL, Khachigian LM, et al. Dominantly inherited constitutional epigenetic silencing of MLH1 in a cancer-affected family is linked to a single nucleotide variant within the $5^{\prime}$ UTR. Cancer Cell. 2011;20(2):200-13

14. Morak M, Ibisler A, Keller G, Jessen E, Laner A, Gonzales-Fassrainer D, et al. Comprehensive analysis of the MLH1 promoter region in 480 patients with colorectal cancer and 1150 controls reveals new variants including one with a heritable constitutional MLH1 epimutation. J Med Genet. 2018:55(4):240-8.

Ready to submit your research? Choose BMC and benefit from:

- fast, convenient online submission

- thorough peer review by experienced researchers in your field

- rapid publication on acceptance

- support for research data, including large and complex data types

- gold Open Access which fosters wider collaboration and increased citations

- maximum visibility for your research: over $100 \mathrm{M}$ website views per year

At $B M C$, research is always in progress.

Learn more biomedcentral.com/submissions 